\title{
Design on the Blended Teaching Model of "MOOC + SPOC + Entity Classroom" in Colleges and Universities
}

\author{
Peng Pei \\ School of Marxism, Jianghan University, Wuhan, Hubei 430056, China \\ Corresponding author. Email: 1664798059@qq.com
}

\begin{abstract}
The blended teaching model of "MOOC + SPOC + entity classroom" integrates traditional entity classroom with online teaching.It effectively combines the positive factors of MOOC, SPOC and entity classroom to realize complementary advantages.It will not only improve the teaching ability of teachers, but also comprehensively enhance the learning effect of students, then promotes the further advancement of higher education teaching reform.
\end{abstract}

Keywords: blended teaching model; MOOC; SPOC; entity classroom

\section{INTRODUCTION}

Massive Open Online Courses (MOOC) has developed rapidly in recent years. Although MOOC has many advantages such as rich resources, open access, and freedom to learn, there are also some deficiencies such as low completion rate, lack of individualized counseling, single test form. As a small-scale restricted online course, SPOC (Small Private Online Course) can avoid the disadvantages of MOOC to some extent, but it also has the problem of effective connection with entity classroom.Compared with the online open class, the traditional entity class in Colleges and universities has the advantages of effective face-to-face communication between teachers and students. Therefore, the blended teaching model of "MOOC + SPOC + entity classroom" is implemented in colleges and universities to integrate traditional face-to-face entity classroom with online teaching.It not only takes advantage of traditional classroom teaching and online teaching under information technology, but also effectively integrates various teaching media, teaching methods and teaching service platforms with the learning environment of colleges and universities.By effectively combining the positive factors of them, the blended teaching model of "MOOC + SPOC + entity classroom" can improve the teaching ability of teachers and enhance the learning effect of students, then promote the further advancement of higher education teaching reform.

\section{THE USE OF MOOC AND SPOC IN COLLEGES AND UNIVERSITIES}

In 2008, Dave Cormier and Professor Bryan Alexander first proposed MOOC (Massive Open Online Courses). Its original idea was to make course resources free to the public with the help of information technology and network tools. The basic mode of MOOC teaching in colleges and universities is that teachers make the knowledge points which the course needs to explain into a video, upload it to a specific network platform for students to watch and study before class, and then let students discuss in class. Discussions can take place between teachers and students or between students. Some scholars call this form "flipping the classroom", which means that it reverses the traditional "from classroom to extracurricular" teaching sequence to "from extracurricular to classroom". It promotes the sharing of curriculum resources on campus to the world. For college education, MOOC improves the traditional model of learning, further establishes studentcentered teaching thinking and concepts, and breaks through the limitation of teaching time and space.Therefore, its birth and development are widely used by college educators. It combines the traditional college teaching mode with the contemporary high-tech achievements, which is conducive to promoting the college teaching to conform to the trend, keep pace with the Times.

However, with the large-scale use of this model in college teaching, practitioners found some practical problems that the MOOC does not interface well with the traditional teaching methods of colleges and universities. First of all, the operation of MOOC mode has the problem of integrity test.In traditional entity classroom, whether teaching or examination, teachers and students can communicate with each other face to face, which can effectively supervise students.MOOC model is difficult to achieve effective supervision.Therefore, there is still no good screening and restraint mechanism for students to find someone else to replace them in the process of study or examination.Secondly, the teaching content and form of MOOC model are still single.At present, the use of MOOC in university education is like a large-scale network broadcast. As Bates, a famous scholar of educational technology and distance education, points out, it is "a very old and outdated behaviorism teaching method that relies on information transmission, computer-based assessment of homework and peer evaluation".Thirdly, the emergence 
of MOOC has challenged the learning style of college students.Because MOOC chooses an open education model, there are almost no restrictions on student admission conditions, which will lead to lack of targeted teaching.And the learners who have no relevant professional foundation can not achieve the expected effect after the elective course, which makes it difficult to complete the normal teaching task

In order to make up for the shortcomings of the MOOC model, Armando Fox, the head of MOOC at the University of California, Berkeley, proposed the SPOC model. SPOC is an abbreviation of Small Private Online Course in English, which is a concept corresponding to MOOC, and is a more refined "traditional integrated online education" course. Under the SPOC model, the size of students is relatively small, even equal to the number of traditional classroom teaching, and some restrictive admission standards are set for students. Only students who meet the corresponding standards are eligible to participate in SPOC related courses. The application of SPOC can make teachers focus on the exploration of differentiated and personalized teaching methods, which is a beneficial innovation and extension for MOOC. ${ }^{[1]}$

\section{THE DESIGN IDEA ON BLENDED TEACHING MODEL OF "MOOC + SPOC + ENTITY CLASSROOM"}

The overall design idea of the "MOOC + SPOC + entity classroom" blended teaching model is to use the online classroom and entity classroom platforms to promote the deep integration of online teaching and offline teaching, and realize the complementary advantages of online teaching and entity classroom.Specifically, it is to embed the MOOC high-quality curriculum resources into the SPOC curriculum structure. Using teaching links, curriculum design, and evaluation methods of SPOC, it mainly focus on entity classroom teaching, supplemented by network guidance.Through the combination of online and offline teaching,the blended teaching model can give full play to the leading role of teachers and the main position of students, and give full play to the main position of students. It is helpful for students to play their main role under the guidance and promotion of teachers.Using a variety of teaching methods to guide students to carry out online self-learning before class, inquiry in class and extended learning after class, the blended teaching model can effectively help students absorb knowledge and improve their ability.In the collaborative interaction between teachers and students, it can promote the improvement of teachers' ability.

In the blended teaching mode of the "MOOC + SPOC + entity classroom", MOOC provides a learning platform and high-quality curriculum resources; entity classroom provide a physical environment for teacher-student interaction, student-student cooperation and exploration; SPOC provides a virtual platform for teachers to guide, answer questions, monitor, examine and evaluate, and for students to learn, think, discuss and explore. ${ }^{[2]}$

Firstly, MOOC, SPOC, and entity classroom support each other. MOOC provides high-quality learning resources for SPOC and entity classroom. SPOC can introduce one or more courses into the SPOC platform in whole or in part as required by copyright, as a recommended resource for users to learn independently. Teachers can embed MOOC curriculum resources into teaching activities in entity classroom teaching as an important supplementary resource for classroom learning or discussion. Moreover, the entity classroom itself is an important link and component of the SPOC teaching model.

Secondly, MOOC, SPOC and entity classroom support blended teaching. (1) MOOC provides resource support for blended teaching, that is, provides resource support by exporting high-quality curriculum resources to the SPOC platform or entity classroom. (2) SPOC provides platform and model support for blended teaching. On the one hand, students can enter the SPOC platform under the guidance of teachers to study, self-test and take exams according to the arrangement of teachers. On the other hand, teachers can observe students' learning dynamics through SPOC platform, supervise and urge students' learning activities, and organize online examination as an important reference data for final assessment and evaluation. SPOC provides model support for blended teaching, which means that the construction of blended teaching mode takes SPOC teaching links and teaching processes as the model and framework, and then integrates MOOC resources and entity classroom to form a complete and systematic education and teaching framework. ${ }^{[3]}$ (3)The entity classroom provides material support and practical support for blended teaching. Material support refers to the provision of physical facilities such as classrooms, teaching aids, tables and chairs, textbooks, multimedia for teaching activities in entity classrooms. Practical support is for students to carry out independent learning, cooperative learning, inquiry learning and participation in discussions in the entity classroom under the guidance and organization of teachers, experiment, essay writing, project research and other learning activities.

\section{DESIGN ON BLENDED TEACHING MODEL OF "MOOC + SPOC + ENTITY CLASSROOM"}

The blended teaching model of "MOOC + SPOC + entity classroom" includes three basic stages: preliminary preparation, implementation of blended teaching, and teaching evaluation.

\subsection{Preliminary preparation}

Preliminary preparation is the beginning of the blended teaching model, which directly determines the success of teaching activities. 
Firstly, analyze the learning objects. The learning object is the main body of the learning activity. The analysis of the learning object mainly includes the analysis of learner preparation knowledge, learning characteristics and learning style. In other words, it is important to understand the relevant knowledge and skills that the learners already have, as well as the knowledge, attitudes and cognitive preferences of the course content. Different majors and students in different grades have different requirements for learning resources. For example, lower grades require systematization and attractiveness, while higher grades pay more attention to the pertinence and practicality of the course content.

Secondly, formulate the overall teaching goals of the curriculum. In the blended teaching mode, not only the overall teaching goals of the course should be given, but also specific and detailed phase goals should be formulated for different stages of learning. In the process of goal setting, we must combine the characteristics of specialization of professional courses in the lower grades, pay attention to the needs of the training of theoretical application levels in the higher grades, and set different stages of teaching goals according to different learning subjects and curriculum requirements.

Thirdly, design the teaching process.It is necessary to design the teaching process in combination with the characteristics of teaching objectives, teaching contents and online resources, determine and divide the content suitable for online self-study, interactive learning between offline classroom teachers and students, practical or practical auxiliary teaching. it is necessary to optimize resource allocation, plan and organize teaching links, steps, methods and special situation intervention mechanism.

\subsection{Implement Blended Teaching}

In the blended teaching mode of "MOOC + SPOC + entity classroom", teachers guide, urge and assist students, while students seek advice from teachers, discuss with teachers and cooperate with teachers, so as to complete learning tasks and achieve teaching objectives in communication and interaction.Teaching and learning promote each other throughout the whole process of blended teaching activities.

First of all, teachers actively guide students to prepare before class.At this stage, teachers implant high-quality MOOC resources into SPOC platform, guide students to learn, monitor students' learning progress through SPOC platform, and solve students' problems in time.In this stage, the core task of students is "autonomous learning", that is, online learning of MOOC courses recommended by teachers, and self-test through set exercises, find difficult problems, conduct online communication. ${ }^{[4]}$

The middle stage is the central link of the whole teaching activity. At this stage, the primary task of the teacher is to "research", that is,to Organize students to participate in learning research, and help students to solve questions, so as to help students acquire knowledge and enhance their ability.Teachers can combine the situation of students' online learning with the pre-class stage, select targeted teaching methods, set the most important and difficult points of classroom teaching, and guide students to master the key points and break through the difficult points. The task of students is "collaborative learning", that is, under the control of problem consciousness, they listen attentively, actively participate in various learning activities organized by teachers, actively participate in the cooperation, communication and interaction between teachers and students, students and students, conduct indepth exploration and learning, and deeply understand knowledge points in various activities. Whether students can really participate in the activities organized by teachers depends on whether teachers' classroom design is close to students' reality, whether it can meet students' learning needs, and whether it can help students to complete knowledge accumulation and structure.

In the after class stage, the main task of teachers is to "promote learning".On the one hand, teachers take measures to supplement and improve the activities in the first two stages, and consolidate and expand them through online discussion, excellent results display and afterschool exploration. On the other hand, according to the curriculum planning, teachers arrange students to carry out online learning programs after class. The core task of students in this stage is "Inquiry Learning", that is to reorganize and integrate the acquired knowledge and information, participate in practical activities, and strive to lead knowledge to practice and promote the transfer of knowledge to practice.Teachers "'promoting learning" and students' "inquiring learning" are interrelated and closely cooperate.

\subsection{Teaching Evaluation}

Teaching evaluation is an assessment of the results of students' learning activities, which is not only related to the teaching effectiveness of teachers, but also to the academic performance of students. The feedback results also provide an important reference for improving teaching strategies. The teaching evaluation under the blended teaching mode of "MOOC + SPOC + entity classroom" runs through the whole teaching process. Its evaluation system emphasizes that staged evaluation and comprehensive evaluation complement each other,which makes the evaluation structure more scientific and reasonable, and the evaluation results more comprehensive and objective. ${ }^{[5]}$

The evaluation activities before class mainly refer to the online preview, preparation and practice before class. The purpose is to guide and urge students to complete the knowledge preparation before class. The evaluation elements include students' participation, learning enthusiasm and knowledge preparation.The evaluation activities in class mainly focus on students' participation in classroom learning and testing. The purpose of the evaluation activities is to organize students to participate in the discussion and urge students to master classroom knowledge and improve their learning ability.The 
evaluation factors include students' participation awareness and ability in classroom learning, knowledge acquisition, emotional involvement and ability improvement.

The evaluation activities after class mainly focus on the deepening, expansion and application of knowledge. The purpose is to consolidate the knowledge learned in class and promote the transformation of theoretical knowledge into practical actions. The evaluation elements are mainly the completion of homework. Different from the evaluation direction of the periodic evaluation, the direction of the comprehensive evaluation is to grasp the students' learning of the course in a certain period through some form of testing, and give the students a corresponding assessment score as a measure of their learning status. Its evaluation elements are knowledge points and knowledge system construction.

The evaluation method can be a combination of online and offline assessment methods. Online assessment can be achieved through the use of technical methods on the SPOC platform or the MOOC platform.It includes not only the evaluation of online preview, preparation and practice before class, but also the introduction of MOOC resources in class to carry out online learning and relevant investigation and evaluation.It also includes learning and evaluating the students' online learning, discussion, problem set and homework through SPOC platform or MOOC platform after the lecture. ${ }^{[6]}$ Offline assessment is the assessment and evaluation of student learning in the entity classroom teaching process and after-school assignments and practices.It includes the assessment and evaluation of students' enthusiasm, ability to participate and effect of participating in group cooperative learning, discussion, experiment, exploration project in the entity classroom.It also includes the assessment and evaluation of students' homework and practice after class.

\section{CONCLUSION}

In the era of highly developed information technology, higher education is also facing profound changes. The blended teaching model of "MOOC + SPOC + entity classroom" effectively integrates traditional entity classroom teaching in colleges and universities with online teaching. It not only takes advantage of traditional classroom teaching and online teaching under information technology, but also effectively integrates various teaching media, teaching methods and teaching service platforms with the learning environment of colleges and universities. Under the blended teaching mode of "MOOC + SPOC + entity classroom" , both the teaching ability of teachers and the learning ability of students will be comprehensively improved. The development of the blended teaching model will help teachers use modern information technology, and students' learning interest is stimulated during the participatory and experiential learning process, their learning enthusiasm is improved, and their autonomous learning ability is continuously enhanced. All this will improve the teaching effect of higher education and promote the further advancement of higher education teaching reform.

\section{REFERENCES}

[1] Chen R, Yang C. (2015) Blended Learning for SPOC. J. Distance Education in China.,5:42-47.

[2] Yao L.X., Zhou G.W. (2018) Design and teaching effect analysis of SPOC Blended teaching mode in Colleges and universities.J. Academic Journal of education., 12: 92-100.

[3] Ma L. (2018) Construction and application of SPOC online teaching platform based on MOOC. J.Computer Knowledge and Technology.,14:166-170.

[4] Zeng M.X, Li G.P, Zhou.Q.P. (2015) From MOOC to SPOC: Construction of a Deep Learning Model.J. China Educational Technology., 11: 28-34.

[5] Liu Y.M. (2015) Chinese higher education reform under the wave of MOOC.J.Higher education of social science., 9: 23-27.

[6] Xu, Y. N. (2015) The mode reform of superior education in the MOOC times. J. Higher Education of Social Science., 8:32-36. 